$p$-ISSN 1693-9484, $e$-ISSN : 2621-8313

Majalah Ilmiah Bahari Jogja (MIBJ)

Vol. 17 No. 2, Juli $2019 \quad$ (27-40)

DOI : $10.33489 /$ mibj.v17i2.207

(C) 2019 Akademi Maritim Yogyakarta

\title{
Analisis Pengaruh Citra Destinasi Dan Lokasi Terhadap Minat Berkunjung Kembali
}

\author{
Siti fatimah ${ }^{1 *}$ \\ ${ }^{1}$ Politeknik API Yogyakarta, Jl. Wisata Babarsari TB XV/15 Yogyakarta \\ * Corresponding Author. E-mail : Zeaty29@gmail.com. Hp:+6281238593600
}

\begin{abstract}
Abstrak
Penelitian ini bertujuan untuk mengetahui : 1.Untuk mengetahui pengaruh antara Citra Destinasi dan Lokasi terhadap Minat Berkunjung Kembali secara serempak,2.Untuk mengetahui pengaruh antara Citra Destinasi dan Lokasi terhadap Minat Berkunjung Kembali secara parsial, 3.Untuk mengetahui antara Citra Destinasi dan Loksai manakah yang paling berpengaruh terhadap Minat Berkunjung Kembali. Populasi dalam penelitian ini adalah pengunjung atau wisatawan yang datang ke Ledok Sambi Eco Playground Kaliurang. Teknik pengambilan sampel secara convenience sampling. Convenience sampling merupakan metode pengumpulan data dari responden, yang didasarkan kepada kesediaan menjadi responden yang dapat menyediakan dan mampu memberikan informasi yang memadai kepada peneliti. Dan di ambil sampel sebanyak 100 responden. Alat uji instrumen menggunakan SPSS for Windows 17.0 dan untuk menguji hipotesis menggunakan regresi linear berganda. Hasil dari penelitian ini berdasarkan hasil uji $\mathrm{F}$ menunjukkan Citra destinasi dan lokasi secara simultan berpengaruh terhadap minat berkunjung kembali. Berdasarkan hasil uji t, Citra destinasi berpengaruh positif signifikan terhadap minat berkunjung kembali, sedangkan Lokasi berpengaruh positif namun tidak signifikan terhadap minat berkunjung kembali. Citra Destinasi berpengaruh paling dominan terhadap Minat Berkunjung Kembali.
\end{abstract}

\section{Kata kunci : Citra destinasi, Lokasi, Minat berkunjung kembali}

\begin{abstract}
This study aims to find out : 1.To find out the effect of the Destination Image and Location on the Interest to Revisit simultaneously, 2. To find out the influence of the Destination Image and Location on the Interest to Revisit partial, 3. To find out between the Destination Image and Loksai which most influence the Return Visit Interest. The population in this study is visitors or tourists who come to Ledok Sambi Eco Playground Kaliurang. Sampling technique by convenience sampling. Convenience sampling is a method of collecting data from respondents, which is based on the willingness to be respondents who can provide and are able to provide adequate information to researchers. And taken a sample of 100 respondents. Instrument test equipment uses SPSS for Windows 17.0 and to test hypotheses using multiple linear regression. The results of this study based on the results of the F test show the destination image and location simultaneously influence the interest in returning. Based on the results of the $t$ test, the image of the destination has a
\end{abstract}


significant positive effect on the interest in revisiting, while the location has a positive but not significant effect on the interest in returning. Destination image has the most dominant influence on Returning Interests.

\section{Keywords: Destination image, location, interest in returning}

\section{PENDAHULUAN}

Kota Yogyakarta terkenal sebagai Kota budaya, Kota pendidikan dan Kota wisata adalah tempat yang sangat nyaman dan memiliki beragam keunikan yang tak habis untuk di eksplore dan dikembangkan. Saat ini banyak sekali jenis wisata yang dikemas dengan berbagai macam tujuan agar lebih dapat mengakomodir keinginan para wisatawan. Salah satu hal yang menarik adalah jenis wisata yang dikemas tidak hanya untuk tujuan wisata tetapi merupakan wisata minat khusus yang sekarang mulai berkembang di kalangan para pelaku wisata, diantaranya adalah paket wisata outbond, camping maupun AMT ( Achievement Motivation Training ).

Ledok Sambi adalah sebuah desa yang berada di kaki Gunung Merapi, merupakan desa yang sangat indah dan sejuk, dengan lingkungan masyarakat pedesaan yang ramah menjadikan desa ini merupakan salah satu destinasi unggulan dinas pariwisata yaitu sebagai desa wisata, yang terkenal sebagai desa wisata Sambi. Desa Sambi memiliki potensi yang layak dijadikan sebagai desa wisata diantaranya adalah kondisi alamnya yang indah, masyarakatnya yang masih menjunjung tinggi nilai nilai tradisi, suasana pedesaan yang masih alami serta memiliki berbagai atraksi wisata penunjang kegiatan wisata. Desa Sambi sudah memiliki citra sebagai desa wisata yang terkenal dengan berbagai potensinya. Citra desa wisata Sambi yang baik tak lepas dari peran dinas pariwisata dalam kegiatan promosinya, maupun letak geografis desa wisata Sambi sendiri yang sangat strategis yaitu ada di lereng Gunung Merapi dan dekat dengan tempat wisata Kaliurang Yogyakarta.

Di dalam desa wisata Sambi terdapat Eco playground yang menjadi salah satu tujuan wisata minat khusus bagi para wisatawan, Eco playground ini memiliki berbagai paket khusus yang dapat dipilih oleh wisatawan yang ingin mengikuti kegiatan seperti camping, outbond, maupun AMT . Kegiatan dapat dilakukan bersama keluarga, sekolah, komunitas maupun instansi. Penawaran jenis kegiatan yang dilakukan disesuaikan dengan kemauan dan tujuan dari para peserta. Fasilitas fasilitas pendukung kegiatan tersedia untuk memudahkan akses dan kegiatan peserta. Fasilitas yang tersedia ada di dalam lingkungan maupun di luar lingkungan Ledok Sambi Eco playground. Fasilitas tersebut diantaranya adalah tempat parkir, sitting area,hall, toilet dan kamar mandi, makanan dan minuman, peralatan penunjang kegiatan, dan arena permainan.

Banyaknya pilihan kegiatan yang sesuai minat pengunjung dan citra lokasi yang bagus membuat ledok sambi Eco playground sangat diminati oleh para wisatawan untuk datang dan menikmati berbagai kegiatan di sini . Pengunjung tidak hanya dapat menikmati suasana desa yang alami dan exotic tapi juga dapat ikut serta dan terjun langsung dalam berbagai kegiatan yang akan menambah wawasan dan merefresh suasana hati . 
Sesuai dengan permasalahan diatas, maka yang menjadi tujuan dari penelitian ini adalah : 1.Untuk mengetahui pengaruh antara Citra Destinasi dan Lokasi terhadap Minat Berkunjung Kembali secara serempak, 2.Untuk mengetahui pengaruh antara Citra Destinasi dan Lokasi terhadap Minat Berkunjung Kembali secara parsial, 3.Untuk mengetahui antara Citra Destinasi dan Loksai manakah yang paling berpengaruh terhadap Minat Berkunjung Kembali.

Menurut Tasci dan Konzak (2006:304), citra destinasi di artikan sebagai persepsi individu terhadap karakteristik destinasi yang dapat dipengaruhi oleh informasi promosi dan media masa serta banyak faktor lainnya. Lopes (2011: 307 308), mendefinisikan konsep citra destinasi sebagai ekspresi dari semua pengetahuan obyektif, prasangka, imajinasi dan pikiran emosional seorang individu atau kelompok tentang lokasi tertentu.

Banyai (2009:17-18) mengemukakan Kerangka kerja dari citra destinasi terdiri dari tiga rangkaian komponen yang berbeda yang dibutuhkan dalam proses pembentukan citra tujuan. Kerangka kerja ini berdasar kerangka kerja sebelumnya yang telah distrukturkan oleh Echtner dan Ricthie (1991) yaitu : 1)Cognitive image, terdiri dari kualitas pengalaman yang didapat oleh para wisatawan, atraksi wisata yang ada di suatu destinasi, lingkungan tersebut, dan tradisi budaya dari destinasi tersebut. 2)Affective image, terdiri dari atraksi yang menyenangkan, membangkitkan, santai, dan menarik ketika di suatu destinasi. 3)Unique image, terdiri dari lingkungan alam, kemenarikan suatu destinasi dan atraksi lokal yang ada di destinasi tersebut.

Lokasi menurut Lupiyoadi (2013:61), merupakan keputusan yang dibuat perusahaan dimana perusahaan harus bertempat dan beroperasi. Sedangkan Kasmir (2012:129) berpendapat bahwa lokasi merupakan tempat melayani konsumen, dapat pula diartikan sebagai tempat untuk menjangkau barang-barang dagangnnya.

Menurut Tjiptono (2002:92) pemilihan tempat/lokasi fisik memerlukan pertimbangan cermat terhadap faktor-faktor berikut: Akses, Visibilitas, Lalu lintas (traffic), Ekspansi, Lingkungan, dan Persaingan.

Dalam hal ini teori minat berkunjung ulang diambil dari teori minat beli ulang terhadap suatu produk, sehingga dalam beberapa kategori minat berkunjung dapat diaplikasikan terhadap minat beli. Minat adalah dorongan untuk memotivasi seseorang melakukan tindakan (Setyo Putra, 2015: 3). Konsumen atau pelanggan yang puas akan melakukan kunjungan ulang pada waktu yang akan datang dan memberitahukan kepada orang lain atas jasa yang dirasakan (Fornell dalam Nuraeni, 2014: 4).

Minat kunjung ulang merupakan suatu bentuk kepuasan yang kemudian akan mendorong kunjungan selanjutnya, yang kemudian akan membentuk rasa loyalitas terhadap diri konsumen. Kesesuaian akan kebutuhan dan penawaran produk akan menimbulkan kepuasan kepada konsumen, oleh karena itu akan menimbulkan minat beli ulang konsumen di waktu mendatang.

Penelitian Y Galih Handawan (2015), menunjukkan citra destinasi pariwisata Waduk Sermo berpengaruh positif terhadap minat wisatawan untuk berkunjung kembalu ke destinasi pariwisata Waduk Sermo. Penelitian di lakukan oleh Wahyunita Nur (2016), menunjukkan bahwa lokasi, keragaman produk, dan harga secara simultan berpengaruh signifikan terhadap minat beli konsumen. Hasil Uji 
parsial menunjukkan bahwa lokasi tidak berpengaruh signifikan, sedangkan keragaman produk, dan harga berpengaruh positif dan signifikan terhadap minat beli konsumen. Faktor yang paling berpengaruh dominan adalah variabel harga.

Berdasarkan penjelasaan tersebut, maka keranga pemikiran dalam penelitian ini digambarkan sebagai berikut :

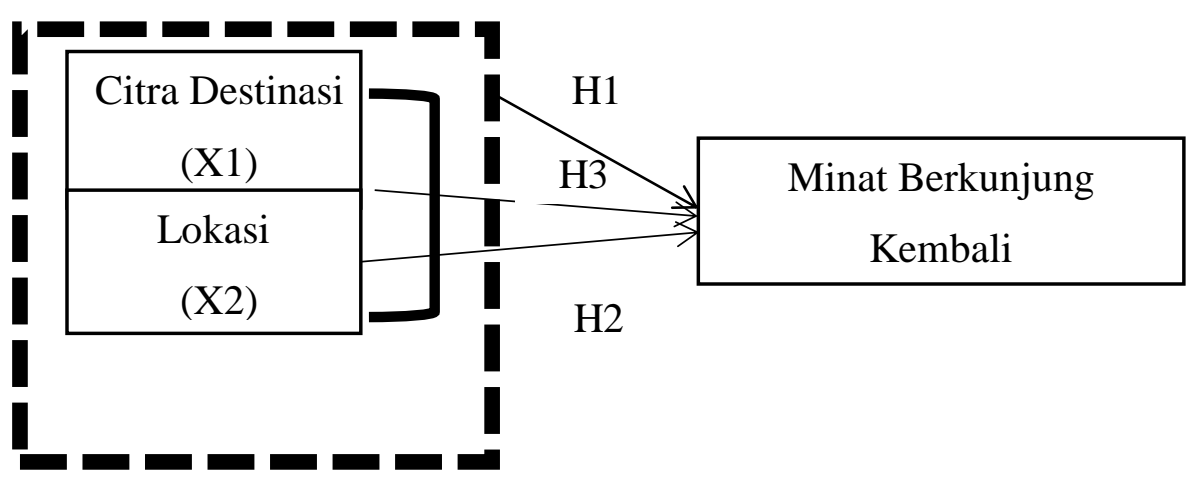

Gambar 1. Kerangka pemikiran

\section{METODE}

A. Subyek dan Obyek Penelitian

Subyek penelitian ini adalah pengunjung/wisatawan yang datang ke Ledok Sambi Eco Playground Kaliurang. Obyek Penelitian ini adalah Citra Destinasi, Lokasi dan Minat Berkunjung Kembali wisatawan Ledok Sambi Eco Playground Kaliurang.

B. Populasi dan sampel

Populasi dalam penelitian ini adalah pengunjung atau wisatawan yang datang ke Ledok Sambi Eco Playground Kaliurang. Sampel yang diambil dalam penelitian ini adalah pengunjung Ledok Sambi Eco Playground Kaliurang yang melakukan outbound. Sampel yang di ambil sebanyak 100 responden, dengan menggunakan teknik pengambilan sampel secara convenience sampling. Convenience sampling merupakan metode pengumpulan data dari responden, yang didasarkan kepada kesediaan menjadi responden yang dapat menyediakan dan mampu memberikan informasi yang memadai kepada peneliti.

C. Variabel Penelitian

Dalam penelitian ini terdiri dari satu variabel dependen 2 variabel independen (bebas). Variabel -variabel tersebut adalah sebagai berikut : 1)Variabel independen(bebas) : Citra destinasi dan lokasi 2)Variabel dependen(terikat) : Minat berkunjung kembali.

D. Jenis dan metode pengumpulan data

Jenis data yang di gunakan dalam penelitian ini adalah data primer, karena jenis data yang di gunakan adalah primer, maka metode yang di gunakan adalah pengumpulan data secara langsung. Dalam penelitian ini data dikumpulkan dengan menyebarkan kuesioner yang berisi sejumlah pernyataan kepada para responden.

Metode pengumpulan data dalam penelitian ini menggunakan kuesioner. Pengukuran variabel dilakukan dengan skala Likert yang menggunakan skoring. 
E. Alat Analis

Dalam penelitian ini penulis menggunakan metode analisis regresi linier berganda yaitu analisis tentang pengaruh variabel bebas $(\mathrm{X})$ yang lebih dari satu terhadap variabel terikat (Y). Alat uji instrumen menggunakan program SPSS release 17.0 for windows.

F. Uji Instrumen

1. Uji Validitas dan Uji Reliabilitas

Pengujian validitas dalam penelitian ini menggunakan rumus korelasi yaitu dengan cara mengkorelasikan setiap butir dengan skor totalnya menggunakan rumus pearson product moment. Uji reliabilitas ini mengguanakan rumus alpha cronbach.

2. Uji F statistika dan Uji T statistika

Pengujian secara serentak (simultan) menggunakan uji $\mathrm{F}$ statistik untuk mengetahui apakah terdapat pengaruh atau tidak antara variabel bebas secara bersama-sama terhadap variabel terikatnya. Jika F hitung lebih besar dari $\mathrm{F}$ tabel, maka terdapat pengaruh antara variabel bebas secara bersamasama terhadap variabel terikat.

Uji T ini di lakukan untuk mengetahui apakah ada pengaruh antara variabel bebas dengan variabel terikat secara parsial. jika t-hitung lebih besar dari t-tabel, maka variabel bebasnya mempunyai pengaruh secara parsial terhadap variabel terikat, demikian pula sebaliknya.

3. Koefisien determinasi dan Metode stepwise

Koefisien determinasi Untuk mengukur poporsi/presentasi sumbangan dari seluruh variabel bebas yang meliputi citra destinasi (X1) dan Lokasi (X2) yang terdapat dalam model regresi terhadap variabel terikat minat berkunjung kembali (Y).

Metode stepwise digunakan bila analisis regresi yang digunakan secara bertahap. Tujuannya adalah untuk mencari variabel bebas atau variabel prediktor mana yang pengaruhnya paling besar.

\section{HASIL DAN PEMBAHASAN}

1. Karakteristik responden

Berdasarkan jenis kelaminnya, maka responden dapat di kalifikasikan menjadi 2 yaitu responden laki-laki dan perempuan. Hasil analisis data karakteristik responden berdasarkan jenis kelaminnya ditunjukkan pada tabel berikut :

Tabel 1 Jenis Kelamin Responden

\begin{tabular}{|l|c|c|}
\hline \multirow{2}{*}{ Jenis kelamin } & \multicolumn{2}{|c|}{ Jumlah } \\
\cline { 2 - 3 } & Dalam angka (orang) & Presentase (\%) \\
\hline Perempuan & 59 & 59 \\
\hline Laki-laki & 41 & 41 \\
\hline Jumlah & 100 & 100 \\
\hline
\end{tabular}

Sumber : Data primer diolah, 2018 
Berdasarkan tabel 1 diatas dapat diketahui bahwa dari 100 responden yang diambil sebagai sampel pada penelitian ini dapat di ketahui bahwa responden terbanyak dalam penelitian ini mayoritas Perempuan yaitu jumlah 59 orang $(59 \%)$ sedangkan responden laki- laki berjumlah 41 orang $(41 \%)$.

Hal ini menunjukkan bahwa mayoritas pengunjung di Ledok Sambi Eco Playground adalah perempuan.

Tabel 2 Asal Kota Responden

\begin{tabular}{|c|c|c|}
\hline \multirow{2}{*}{ Asal Kota } & \multicolumn{2}{|c|}{ Jumlah } \\
\cline { 2 - 3 } & Dalam angka (orang) & Presentase (\%) \\
\hline Luar Kota Yogyakarta & 73 & 73 \\
\hline Kota Yogyakarta & 27 & 27 \\
\hline Jumlah & 100 & 100 \\
\hline
\end{tabular}

Sumber : Data primer diolah, 2018

Berdasarkan tabel 2 diatas menunjukkan bahwa sebagian besar responden berasal dari luar kota Yogyakarta yaitu sebanyak 73 orang atau sebesar $73 \%$ sedangkan responden yang berasal dari kota Yogyakarta sebanyak 27 orang atau sebesar $27 \%$.

Berdasarkan data tersebut dapat di ketahui bahwa sebagian besar responden berasal dari luar kota Yogyakarta yaitu sebesar $73 \%$.

Tabel 3 Usia Responden

\begin{tabular}{|l|c|c|}
\hline \multirow{2}{*}{ Usia } & \multicolumn{2}{|c|}{ Jumlah } \\
\cline { 2 - 3 } & Dalam angka (orang) & Presentase (\%) \\
\hline Di bawah 20 tahun & 79 & 79 \\
\hline 21 tahun & 15 & 15 \\
\hline Di atas 22 tahun & 6 & 6 \\
\hline \multicolumn{1}{|c|}{ Jumlah } & 100 & 100 \\
\hline
\end{tabular}

Sumber : Data primer diolah, 2018

Berdasarkan tabel 3 di atas menunjukkan bahwa sebanyak 79 orang atau sebesar $79 \%$ responden berusia di bawah 20 tahun, 15 orang atau sebesar $15 \%$ berusia 21 tahun dan 6 orang atau sebesar $6 \%$ berusia di atas 22 tahun.

Dari hasil di atas dapat di ketahui bahwa sebanyak 79 orang atau $79 \%$ berusia di bawah 20 tahun. 
Tabel 4 Jumlah Kunjungan Responden

\begin{tabular}{|l|c|c|}
\hline \multirow{2}{*}{ Jumlah Kunjungan } & \multicolumn{2}{|c|}{ Jumlah } \\
\cline { 2 - 3 } & Dalam angka (orang) & Presentase (\%) \\
\hline 1 Kali & 92 & 92 \\
\hline Lebih dari 1 kali & 8 & 8 \\
\hline Jumlah & 100 & 100 \\
\hline
\end{tabular}

Sumber : Data primer diolah, 2018

Dari data tabel 4 diatas dapat di ketahui bahwa jumlah kunjungan responden yang baru 1 kali berkunjung sebanyak 92 orang atau sebesar $92 \%$ dan yang sudah berkunjung lebih dari 1 kali ada sebanyak 8 orang atau sebesar $8 \%$.

Berdasarkan karakteristik jumlah kunjungan dapat di ketahui bahwa sebanyak 92 orang atau sebesar $92 \%$ baru 1 kali berkunjung ke Ledok Sambi Eco Playground.

2. Uji Validitas

a) Uji Validitas Citra Destinasi (X1)

Variabel Citra Destinasi terdiri dari 9 item pertanyaan, berdasarkan hasil uji validitas hasilnya sebagai berikut :

Tabel 5 Hasil Uji Validitas Variabel Citra Destinasi (X1)

\begin{tabular}{|c|c|c|c|}
\hline Butir & Nilai r (correlation) & Nilai Sig & Ket \\
\hline X1.1 & 0,846 & 0,000 & Valid \\
\hline X1.2 & 0,422 & 0,000 & Valid \\
\hline X1.3 & 0,637 & 0,000 & Valid \\
\hline X1.4 & 0,769 & 0,000 & Valid \\
\hline X1.5 & 0,405 & 0,000 & Valid \\
\hline X1.6 & 0,838 & 0,000 & Valid \\
\hline X1.7 & 0,429 & 0,000 & Valid \\
\hline X1.8 & 0,751 & 0,000 & Valid \\
\hline X1.9 & 0,460 & 0,000 & Valid \\
\hline
\end{tabular}

Sumber : Data primer diolah, 2018

Tabel 5 diatas menunjukan bahwa semua butir pernyataan dari variabel Citra Destinasi dinyatakan valid karena semua butir mempunyai korelasi dengan taraf signifikansi $<0,05$ dan nilai $\mathrm{r}^{\text {hitung }}>0,197\left(\mathrm{r}^{\text {tabel }}\right)$.

b) Uji Validitas Lokasi (X2)

Variabel Lokasi terdiri dari 14 item pernyataan, berdasarkan hasil uji validitas hasilnya sebagai berikut : 
Tabel 6 Hasil Uji Validitas Variabel Lokasi (X2)

\begin{tabular}{|c|c|c|c|}
\hline Butir & Nilai r (correlation) & $\begin{array}{c}\text { Nilai } \\
\text { Sig }\end{array}$ & Ket \\
\hline X2.1 & 0,260 & 0,009 & Valid \\
\hline X2.2 & 0,751 & 0,000 & Valid \\
\hline X2.3 & 0,414 & 0,000 & Valid \\
\hline X2.4 & 0,405 & 0,000 & Valid \\
\hline X2.5 & 0,455 & 0,000 & Valid \\
\hline X2.6 & 0,557 & 0,000 & Valid \\
\hline X2.7 & 0,260 & 0,009 & Valid \\
\hline X2.8 & 0,489 & 0,000 & Valid \\
\hline X2.9 & 0,507 & 0,000 & Valid \\
\hline X2.10 & 0,710 & 0,000 & Valid \\
\hline X2.11 & 0,559 & 0,000 & Valid \\
\hline X2.12 & 0,632 & 0,000 & Valid \\
\hline X2.13 & 0,421 & 0,000 & Valid \\
\hline X2.14 & 0,639 & 0,000 & Valid \\
\hline
\end{tabular}

Sumber : Data primer diolah, 2018

Berdasarkan dari data tabel 6 tersebut bahwa $\mathrm{r}^{\text {hitung }}>$ dari $\mathrm{r}^{\text {tabel }} 0,197$ dan mempunyai korelasi dengan taraf signifikansi $<0,05$ jadi semua butir Pernyataan pada variabel lokasi dinyatakan valid dan memenuhi persyaratan validitas.

c) Uji Validitas Lokasi (X2)

Variabel Lokasi terdiri dari 14 item pernyataan, berdasarkan hasil uji validitas hasilnya sebagai berikut :

Tabel 7 Hasil Uji Validitas Variabel Minat Berkunjung Kembali (Y)

\begin{tabular}{|c|c|c|c|}
\hline Butir & Nilai r (correlation) & $\begin{array}{c}\text { Nilai } \\
\text { Sig }\end{array}$ & Ket \\
\hline Y.1 & 0,638 & 0,000 & Valid \\
\hline Y.2 & 0,634 & 0,000 & Valid \\
\hline Y.3 & 0,618 & 0,000 & Valid \\
\hline Y.4 & 0,551 & 0,000 & Valid \\
\hline Y.5 & 0,624 & 0,000 & Valid \\
\hline Y.6 & 0,649 & 0,000 & Valid \\
\hline Y.7 & 0,580 & 0,000 & Valid \\
\hline
\end{tabular}

Sumber : Data primer diolah, 2018

Tabel 7 diatas menunjukan bahwa semua butir pernyataan dari variabel minat berkunjung kembali dinyatakan valid karena semua butir mempunyai korelasi dengan taraf signifikansi $<0,05$ dan nilai $\mathrm{r}^{\text {hitung }}>0,197\left(\mathrm{r}^{\text {tabel }}\right)$. 


\section{Uji Reliabilitas}

Uji reliabilitas dilakukan dengan menggunakan Alpha Cronbach. Hasil uji reliabilitas Alpha Cronbach yang didapat untuk masing-masing variabel ditunjukkan dalam Tabel 8

Tabel 8 Hasil Uji Reliabilitas

\begin{tabular}{|l|c|c|}
\hline \multicolumn{1}{|c|}{ Variabel } & Alpha Cronbach & Ket \\
\hline Citra Destinasi (X1) & 0,786 & Reliabel \\
\hline Lokasi (X2) & 0,762 & Reliabel \\
\hline Minat Berkunjung Kembali (Y) & 0,717 & Reliabel \\
\hline
\end{tabular}

Sumber : Data primer diolah, 2018

Dari diatas bahwa pada ketiga variabel yaitu citra destinasi (X1), lokasi (X2), minat berkunjung kembali (Y) Alpha Cronbach menunjukkan nilai lebih dari 0,7 sehingga dikatakan bahwa instrumen yang digunakan di dalam penelitian memiliki reliabilitas yang baik.

Dari hasil uji validitas dan reliabilitas yang telah dilakukan, maka dapat disimpulkan bahwa kuesioner sudah layak untuk digunakan sebagai instrumen penelitian.

4. Analisis Regresi Linier Berganda

Tabel 9 Hasil pengujian regresi linier berganda

Coefficients $^{a}$

\begin{tabular}{|c|c|c|c|c|c|c|c|}
\hline \multirow[b]{2}{*}{ Model } & \multicolumn{2}{|c|}{$\begin{array}{l}\text { Unstandardized } \\
\text { Coefficients }\end{array}$} & \multirow{2}{*}{\begin{tabular}{|c}
$\begin{array}{c}\text { Standardized } \\
\text { Coefficients }\end{array}$ \\
Beta
\end{tabular}} & \multirow[b]{2}{*}{$\mathrm{t}$} & \multirow[b]{2}{*}{ Sig. } & \multicolumn{2}{|c|}{$95,0 \%$ Confidence Interval for B } \\
\hline & $B$ & Std. Error & & & & Lower Bound & Upper Bound \\
\hline 1 (Constant) & 6.314 & 2.592 & & 2.436 & .017 & 1.169 & 11.458 \\
\hline Citra Destinasi & .357 & .110 & .435 & 3.239 & .002 & .138 & .575 \\
\hline Lokasi & .151 & .083 & .245 & 1.824 & .071 & -.013 & .315 \\
\hline
\end{tabular}

a. Dependent Variable: Minat Berkunjung Kembali

Berdasarkan tabel 9 coefficients diatas maka dapat diperoleh persamaan regresi yaitu :

$$
\mathrm{Y}=6,314+0,357 \mathrm{X} 1+0,151 \mathrm{X} 2
$$

Dari persamaan regresi linier berganda dalam tabel di atas dapat di ketahui bahwa : 1) Kontanta a =6,314 Artinya jika skor variabel citra destinasi, lokasi konstan atau 0, maka skor minat berkunjung kembali nilanya 6,314. 2) Nilai koefisien regresi citra destinasi (b1) yang bertanda positif $(0,357)$ menunjukkan adanya pengaruh yang positif antara citra destinasi dengan minat berkunjung kembali. Artinya jika citra destinasi yang di berikan bagus dan berkesan bagi pengunjung maka keinginan untuk berkunjung kembali akan meningkat. 3) Nilai koefisien regresi lokasi (b2) yang bertanda positif $(0,151)$ menunjukkan adanya pengaruh yang positif antara lokasi dengan minat berkunjung kembali. Artinya jika lokasi yg strategis, aman, nyaman dan 
bearada di lingkungan yang baik maka minat pengunjung untuk kembali di lain waktu akan meningkat.

Dari hasil koefisien regeresi kedua variabel yang bernilai positif, berarti variabel independen tersebut mempunyai pengaruh positif terhadap variabel dependen.

5. Uji F

Tabel 10 Hasil nilai uji F

ANOVA $^{\mathrm{b}}$

\begin{tabular}{|l|r|r|r|c|c|}
\hline Model & Sum of Squares & df & Mean Square & F & Sig. \\
\hline $1 \quad$ Regression & 533.523 & 2 & 266.761 & 35.591 & $.000^{\mathrm{a}}$ \\
Residual & 727.037 & 97 & 7.495 & & \\
Total & 1260.560 & 99 & & & \\
\hline
\end{tabular}

a. Predictors: (Constant), Lokasi, Citra Destinasi

b. Dependent Variable: Minat Berkunjung Kembali

Dari hasil tabel 10 pengolahan data diatas diketahui bahwa nilai F-hitung adalah 35,591 dengan nilai signifikan sebesar 0,000, dan nilai F-tabel adalah 3,090 dengan demikian dapat di simpulkan bahwa F-hitung > F-tabel dengan tingkat signifikan $0,000<0,05(\mathrm{p}<0,05)$, maka Ho ditolak dan Ha diterima berarti variabel-variabel citra destinasi dan lokasi berpengaruh secara simultan terhadap minat berkunjung kembali.

6. Uji T

Tabel 11 Hasil nilai uji $\mathrm{t}$

\begin{tabular}{|l|l|l|c|c|}
\hline \multicolumn{1}{|c|}{ Variabel } & \multicolumn{1}{c|}{ T hitung } & T tabel & Sig & Ket \\
\hline Citra destinasi & 3,239 & 1,660 & 0,002 & Signifikan \\
\hline lokasi & 1,824 & 1,660 & 0,071 & Signifikan \\
\hline
\end{tabular}

Dari hasil olah data di atas diketahui t-hitung masing-masing variabel adalah:

Variabel citra destinasi t-hitung lebih besar dari t-tabel $(3,239>1,660)$ dengan porbalitas $(0,002)$ lebih kecil dari taraf signifikan 0,05 dengan demikinan Ho di tolak dan Ha diterima,artinya variabel citra destinasi mempunyai pengaruh yang signifikan terhadap minat berkunjung kembali dan Variabel lokasi t-hitung lebih besar dari t-tabel $(1,824>1,660)$ dengan porbalitas $(0,071)$ lebih besar dari taraf signifikan 0,05 dengan demikinan Ho di terima dan Ha ditolak, artinya variabel lokasi tidak ada pengaruh yang signifikan terhadap minat berkunjung kembali. 
7. Koefisien determinasi

Tabel 12 Hasil analisis uji koefisien determinasi

\begin{tabular}{|l|c|r|r|r|}
\hline Model & $\mathrm{R}$ & $\mathrm{R}$ Square & $\begin{array}{c}\text { Adjusted R } \\
\text { Square }\end{array}$ & $\begin{array}{c}\text { Std. Error of the } \\
\text { Estimate }\end{array}$ \\
\hline 1 & $.651^{\mathrm{a}}$ & .423 & .411 & 2.738 \\
\hline
\end{tabular}
a. Predictors: (Constant), Lokasi, Citra Destinasi
b. Dependent Variable: Minat Berkunjung Kembali

Dari perhitungan diatas diperoleh nilai besarnya koefisien determinasi adalah 0,411 hal ini menunjukkan bahwa pengaruh variabel independen (citra destinasi dan lokasi) terhadap variabel dependen (minat berkunjung kembali) adalah $41,1 \%$. Sedangkan $58,9 \%$ dipengaruhi oleh variabel lain selain citra destinasi dan lokasi.

8. Metode stepwise

Tabel 13 Hasil analisis metode stepwise

Coefficients $^{a}$

\begin{tabular}{|c|c|c|c|c|c|c|c|}
\hline \multirow[b]{2}{*}{ Model } & \multicolumn{2}{|c|}{$\begin{array}{l}\text { Unstandardized } \\
\text { Coefficients }\end{array}$} & \multirow{2}{*}{$\begin{array}{c}\text { Standardized } \\
\text { Coefficients } \\
\text { Beta }\end{array}$} & \multirow[b]{2}{*}{$\mathrm{t}$} & \multirow[b]{2}{*}{ Sig. } & \multicolumn{2}{|c|}{$\begin{array}{c}95,0 \% \text { Confidence } \\
\text { Interval for B }\end{array}$} \\
\hline & B & $\begin{array}{l}\text { Std. } \\
\text { Error }\end{array}$ & & & & $\begin{array}{l}\text { Lower } \\
\text { Bound }\end{array}$ & $\begin{array}{l}\text { Upper } \\
\text { Bound }\end{array}$ \\
\hline $1 \quad$ (Constant) & 6.314 & 2.592 & & 2.436 & .017 & 1.169 & 11.458 \\
\hline Citra Destinasi & .357 & .110 & .435 & 3.239 & .002 & .138 & .575 \\
\hline Lokasi & .151 & .083 & .245 & 1.824 & .071 & -.013 & .315 \\
\hline
\end{tabular}

a. Dependent Variable: Minat Berkunjung Kembali

Di lihat dari tabel 13 diperoleh variabel yang dominan mempengaruhi minat berkunjung kembali (Y) adalah citra destinasi (X1). Ini dilihat dari nilai uji stepwise yang paling dominan mempengaruhi minat berkunjung kembali (Y) adalah citra destinasi (X1). Ini juga dilihat dari nilai t 3,239 dengan tingkat porbabilitas 0,002 .

\section{SIMPULAN}

\section{Kesimpulan}

Berdasarkan analisis data dan pembahasan hasil penelitian, dapat diambil kesimpulan sebagai berikut :

1. Hasil analisis regerensi linier berganda menghasilkan persamaan regeresi $\mathrm{Y}=6,314+0,357 \mathrm{X} 1+0,151 \mathrm{X} 2$

2. Citra destinasi dan lokasi secara simultan berpengaruh terhadap minat berkunjung kembali ke Ledok Sambi Eco Playground. Berdasarkan hasil uji $\mathrm{F}$ dengan F-hitung $(35,591)>$ F-tabel $(3,090)$ dan tingkat signifikan $0,000<0,05$. 
3. Citra destinasi berpengaruh positif signifikan terhadap minat berkunjung kembali ke Ledok Sambi Eco Playground. Berdasarkan hasil uji t dengan t-hitung $(3,239)>$ t-tabel $(1,660)$ dan dengan tingkat signifikan $0,002<$ 0,05 .

4. Lokasi berpengaruh positif namun tidak signifikan terhadap minat berkunjung kembali ke Ledok Sambi Eco Playground. Berdasarkan hasil uji t dengan t-hitung $(1,824)>\mathrm{t}$-tabel $(1,660)$ dan dengan tingkat signifikan $0,071>0,005$

5. Citra Destinasi berpengaruh paling dominan terhadap Minat Berkunjung Kembali Ledok Sambi Eco Playground. Berdasarkan hasil analisis metode stepwise dengan nilai t 3,239 dengan tingkat porbabilitas 0,002 dan berdasarkan hasil analisis uji koefisien determinasi besarnya koefisien determinasi adalah 0,411 hal ini menunjukkan bahwa pengaruh variabel independen (citra destinasi dan lokasi) terhadap variabel dependen (minat berkunjung kembali) adalah 41,1\%. Sedangkan 58,9\% dipengaruhi oleh variabel lain selain citra destinasi dan lokasi.

\section{Saran}

Dari hasil penelitian, analisis dan kesimpulan diatas berikut beberapa saran yang dapat disampaikan :

1. Perusahaan perlu melakukan evaluasi dan melakukan peninjauan terhadap fasilitas yang akan di gunakan untuk kegiatan (atraksi) sebelum di terapkan ke pengunjung dan menambah beberapa fasilitas umum yang bisa di gunakan pengunjung.

2. Perusahaan perlu melakukan evaluasi terkait dengan kebersihan lingkungan yang ada di sekitar Ledok Sambi Eco Playground, perusahaan bisa menerapkan suatu sistem terkait dengan kebersihan lingkungan agar semua wilayah dan area di ledoksambi terlihat bersih dan nyaman.

3. Bahwa jalan yang menuju ke arah ledok sambi eco playground belum baik, perusahaan bisa meningkatkan perbaikan jalan ke arah lokasi dengan cara bekerjasama dengan pihak terkait dan pemberdayaan masyarakat sekitar untuk bersama sama memperbaiki kualitas jalan.

4. Area parkir ke arah lokasi masih dirasa terlalu jauh, sehingga perlu penataan lokasi parkir agar akses ke lokasi dapat lebih dekat atau terjangkau oleh pelanggan.

5. Perusahaan perlu menambah fasilitas yang mendukung kegiatan agar dapat mengcover semua hal yang dibutuhkan oleh pelanggan sehingga pelanggan merasa lebih nyaman.

6. Perusahaan perlu meningkatkan kepuasan konsumen hal ini dapat dilakukan dengan cara berusaha menggali minat konsumen agar perusahaan dapat memberikan pelayanan yang maksimal pada konsumen.

\section{DAFTAR PUSTAKA}

Algifari.1997. Statistik Induktif Untuk Ekonomi Industry Dan Bisnis.UPP AMP YKPN Yogyakarta. 
Alma, Buchari. 2003. Manajemen Pemasaran dan Pemasaran Jasa. Edisi 2. Bandung: Alfabeta.

Arikunto,Suharsimi.2002. Prosedur Penelitian.Rineka cipta:Jakarta

Banyai , M. (2009). The Image of Tourism Destinations. Waterloo, Canada.

Basiya. R Dan Rozak. H. A. 2012. Kualitas Daya tarik Wisata, Kepuasan Dan Niat Kunjungan Kembali Wisatawan Mancanegara Di Jawa Tengah. Universitas Stikubank. Semarang.

Basu Swastha.(2009). Manajemen Penjualan. Yogyakarta: BPFE

Basu, Swastha DH., Irawan. 2008. Manajemen Pemasaran Modern, Edisi Kedua, Cetakan Ke-tigabelas, Yogyakarta: Liberty Offset.

Engel, F. James ; Roger D. Blackwell; Paul W. Miniard. 2013. Perilaku Konsumen. Jakarta : Binarupa Aksara

Ferdinand, A. 2002. Structural equation modelling dalam penelitian manajemen.

Hartono.2013.SPSS 16.0 Analisis Data Statistika Dan Penelitian.Yogyakarta: Pustaka Pelajar

Indrianto, Nur dan Supomo, Bambang. (2000). Metodologi Penelitan Bisnis Untuk Akuntasi dan Manajemen. Yogyakarta: BPFE Yogyakarta.

Jørgensen, Louise Gylling. (2004) "An analysis of a destination"s image and the language of tourism”. Cand.Ling.Merc. (ii) Thesis Department of English.

Kasmir. 2012. Etika Customer Servis. Jakarta : PT Rajagrafindo Persada

Kotler dan Keller. (2009). Manajemen Pemasaran, Jilid I (ed 13). Jakarta : Erlangga

Kotler, Philip. (2008). Manajemen Pemasaran, Jilid 1. Jakarta : PT. Indeks Kelompok Gramedia.

Lemeshow, Stanley., 1997, Besar Sampel dalam Penelitian Kesehatan, Gadjah Mada University, Yogyakarta.

Levy, Michael \& Weitz, Barton A, (2012). Retailing Management. New York, America : McGraw-Hill/Irwin.

Lin C.H., Duarte, B.M., Deborah, L.K, Jing, S.H. 2007. Examining the Role of Cognitive and Affective Image Predicting Choice Across Natural,Developed, and Theme-Park Destinations. Jurnal of Travel Research, 46:183-194

Lopes, Sérgio Dominique Ferreira. (2011) "Destination image: origins, developments and implications".Polytechnic Institute of Cávado and Ave Portugal.

Lupiyoadi, Rambat, (2013) : Manajemen Pemasaran Jasa. Jakarta : Salemba Empat.

Petrick, James F, et al. 2001. "An Examination of the Determinants of Entertainment Vactioner's Intentions to Revisit, ' in Journal of Travel Research, Vol. 40, Sage Publications, 42-43.

Pike, S. 2008. Destination Marketing. Butterworth-Heineman. Semarang: Universitas Diponegoro.

Sugiyono. (2012), Metode Penelitian Bisnis. Cetakan keenam belas, CV Alfabeta, Bandung;

Sugiyono. (2017). Metode Penelitian Kuantitatif, Kualitatif, dan R\&D. Bandung: Alfabeta 
Tasci, Asli D.A, and Metin Kozak. 2006. Destination brands vs destination images: Do we know what we mean?. Journal of Vacation Marketing, 12 (4), p. 299-185.

Tjiptono, Fandy. (2002). Strategi Pemasaran. Yogyakarta : Andy Offset.

Utami C.W. (2010). Manajemen Ritel : Strategi dan Implementasi Ritel Modern. Jakarta : Sinar Harapan 